\title{
RECREATIONAL WATERFRONT HARBoUR DI BANTEN DENGAN Penekanan Analogi Arsitektur
}

\author{
Nia Damayanti, Agung Kumoro, Hari Yuliarso \\ Program Studi Arsitektur \\ Jurusan Arsitektur Fakultas Teknik \\ Universitas Sebelas Maret Surakarta \\ Email : fishcake_narutokun68@yahoo.co.id
}

\begin{abstract}
Designing Recreational Waterfront Harbour in Banten motivated by the lack of ports in Banten, the issue of the Selat Sunda bridge construction plan, and the tourism potential of the waterfront, so the purpose of this scheme is to get the port design that can provide berthing facilities and activities waterfront recreational activities by applying Architecture Analogy Emphasis to express the shape and movement of water in buildings and harbor area. Design issues are: how the expression form and movement of water can be translated into the design of Recreational Waterfront Harbour. The method used in the design of mass system design, the basic shape and appearance of the harbor is the analogy architectural method of shapes and movement of water. The result obtained is the design of a blend of a port area and waterfront recreation area that expresses the shape and movement of water in the form of basic, mass system and display area.
\end{abstract}

Keywords: Recreational Waterfront, Form and Movement Water, Architecture Analogy.

\section{PENDAHULUAN}

Indonesia merupakan negara kepulauan terbesar di dunia dengan jumlah pulau lebih dari 17.500, panjang garis pantai lebih dari $80.000 \mathrm{~km}$ dan kurang lebih $2 / 3$ dari seluruh wilayahnya adalah perairan. Bentuk Negara kepulauan ini seolah-olah membatasi interaksi antara masyarakat Indonesia, sehingga proses kehidupan di berbagai aspek mendapatkan pengaruh karena adanya pembatas berupa lautan. Kondisi geografis yang demikian mengakibatkan pentingnya peranan transportasi laut seperti pelabuhan. Selain berfungsi sebagai penghubung antar pulau, pelabuhan juga berfungsi sebagai pintu gerbang dan pelancar hubungan antar daerah, pulau bahkan antar benua dan bangsa / Gate Way port (Bambang Triatmodjo, 1996). Provinsi Banten memiliki beberapa pelabuhan diantaranya Pelabuhan Merak. Kondisi Pelabuhan Merak sangat padat dan melebihi batas tampung pelabuhan, sehingga diperlukan pelabuhan baru. Selain itu terdapat isu pembangunan Jembatan Selat Sunda yang dapat menimbulkan berkurangnya pengunjung pelabuhan baru tersebut. Jika isu tersebut terjadi, maka dengan pemanfaatan potensi wisata tepi laut yang dimiliki Provinsi Banten pada perencanaan pelabuhan baru diharapkan dapat menjawab isu tersebut.

Recreational Waterfront Harbour atau Pelabuhan Rekreasi Tepi Laut ini direncanakan dapat memenuhi tuntutan kegiatan berlabuh dan kegiatan rekreasi. Dalam perancangan pelabuhan yang berfungsi sebagai area rekreasi dan sebagai Gate Way port yang terpenting adalah ekspresi bentuk bangunan dan kawasan. Air merupakan obyek umum yang dapat ditemui di pelabuhan. sehingga ditekankan analogi bentuk dan pergerakan air pada penataan massa, bentuk dasar dan tampilan pelabuhan untuk mengekspresikan Recreational Waterfront Harbour.

\section{METODE}

Analogi dapat digunakan dengan bermacam cara, salah satunya adalah sebagai alat komunikasi seseorang didalam mengekspresikan pemikirannya secara tidak langsung (Zarzar,2008). Metode analogi yang digunakan pada perancangan desain tata massa, bentuk dasar dan 
tampilan bangunan adalah metode analogi biologis bentuk dan pergerakan air yang meliputi bentuk dan pergerakan air fold, cusp, ecliptic umbilic, dan hyperbolic umbilic. Proses analogi dari keempat bentuk dan pergerakan air tersebut pada aplikasi tata massa, bentuk dasar dan tampilan adalah sebagai berikut:

\subsection{Pemetaan bentuk dan sifat pergerakan} air

Menentukan bentuk dan sifat dari masing-masing pergerakan air.

\section{Fold}

Bentuk pergerakan air lengkungan dan simetris dengan titik puncak di area tengah. Kecepatan pergerakan cenderung cepat dan stabil karena mendapat dorongan yang cepat saat pertama kali.

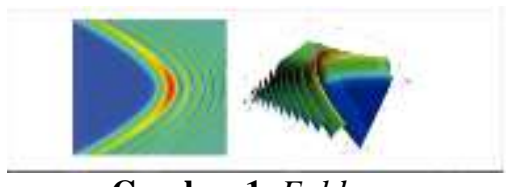

Gambar 1. Fold

(Sumber: Honggo Pius, 2012)

\section{Cusp}

Bentuk pergerakan air lengkungan dan simetris dengan titik puncak di area tengah. Puncak lengkungan relatif meruncing jika dibandingan dengan bentuk fold. Kecepatan pergerakan cenderung lebih cepat dan stabil karena mendapat dorongan yang cepat saat pertama kali.

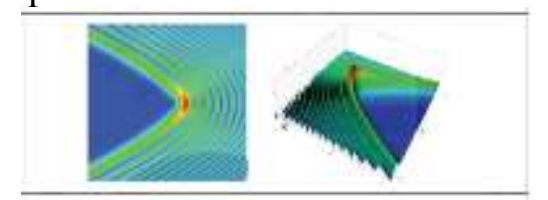

Gambar 2. Cusp

(Sumber: Honggo Pius, 2012)

\section{Ecliptic umbilic}

Bentuk pergerakan air lengkungan dan simetris. Kecepatan semakin besar karena mendapat dorongan dari arah yang berlawanan/lain. Terjadinya pertemuan/tabrakan alur pergerakan yang mengakibatkan titik pertemuan merupakan titik paling tinggi.

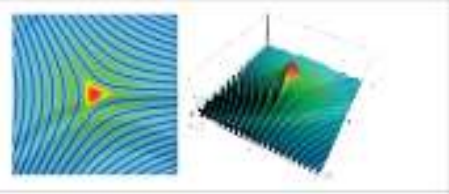

Gambar 3. Ecliptic Umbilic

(Sumber: Honggo Pius, 2012)

\section{Hyperbolic umbilic}

Bentuk pergerakan air lengkungan dan simetris. Kecepatan pergerakan semakan besar karena mendapat dorongan dari arah belakangnya. Terjadinya pertemuan/tabrakan alur pergerakan di belakang yang mengakibatkan terjadinya titik pertemuan di belakang dan pada bagian depan menghilang.

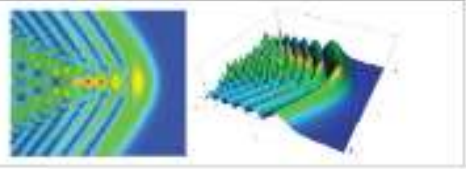

Gambar 4. Hyperbolic Umbilic

(Sumber: Honggo Pius, 2012)

\subsection{Transformasi bentuk dan pergerakan}

air

Mentranformasikan bentuk dan sifat keempat pergerakan air ke dalam bentuk yang lebih sederhana.

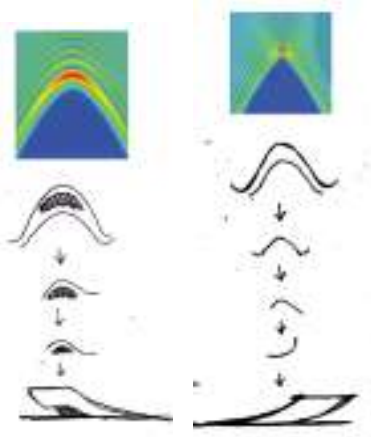

Gambar 5. Trasformasi Fold dan Cusp
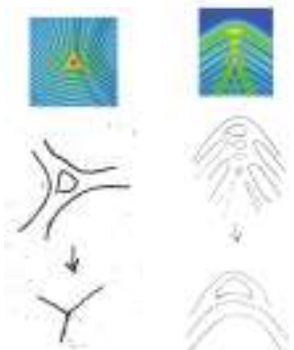

Gambar 6. Trasformasi Ecliptic Umbilic dan Hyperbolic Umbilic 


\subsection{Aplikasi pada desain}

Mengaplikasikan hasil transformasi bentuk dan pergerakan air pada tata massa, bentuk dasar, dan tampilan sesuai karakteristik sirkulasi. Fold dan cusp diaplikasikan pada bangunan terminal pelabuhan karena sifar sirkulasi satu arah yang stabil. Sedangkan ecliptic umbilic dan hyperbolic umbilic diaplikasikan pada Recreational Waterfront karena sifat sirkulasi yang tidak beraturan.

\section{ANALISIS}

\subsection{Analisis Penentuan Kegiatan}

Kegiatan di dalam Recreational Waterfront Harbour dibagi menjadi dua kelompok kategori antara lain:

1. Kegiatan berlabuh berupa bersandar dan berlabuhnya kapal, naik turunnya penumpang dan bongkar muat barang. Pada kelompok kegiatan ini, terbagi menjadi zona pelayanan embarkasi, debarkasi dan pengelolaan.

2. Kegiatan rekreasi berupa kegiatan menikmati pemandangan waterfront dan kegiatan berlabuhnya kapal laut.

\subsection{Analisa Peruangan}

Tabel 1.Kebutuhan Ruang

\begin{tabular}{|l|l|l|}
\hline PELAKU & KEGIATAN & PERUANGAN \\
\hline $\begin{array}{l}\text { Penumpang } \\
\text { embarkasi } \\
\text { dan } \\
\text { debarkasi }\end{array}$ & Parkir & Area Parkir \\
\cline { 2 - 3 } & $\begin{array}{l}\text { Memesan } \\
\text { tiket }\end{array}$ & $\begin{array}{l}\text { R.Pemesanan } \\
\text { tiket }\end{array}$ \\
\cline { 2 - 3 } & $\begin{array}{l}\text { Mengecek } \\
\text { jadwal }\end{array}$ & R.Informasi \\
\cline { 2 - 3 } & $\begin{array}{l}\text { Membeli } \\
\text { souvenir }\end{array}$ & Toko Souvenir \\
\cline { 2 - 3 } & Rekreasi & $\begin{array}{l}\text { Recreational } \\
\text { waterfront }\end{array}$ \\
\cline { 2 - 3 } & Cek in & $\begin{array}{l}\text { R.Pemeriksa- } \\
\text { an tiket, } \\
\text { R.Pemeriksa- } \\
\text { an barang }\end{array}$ \\
\hline & Menunggu & R.tunggu \\
\hline Kapal Laut & $\begin{array}{l}\text { Parkir/Bersa } \\
\text { ndar } \\
\text { Debarkasi } \\
\text { dan } \\
\text { embarkasi }\end{array}$ & Hall penerima \\
\hline
\end{tabular}

\begin{tabular}{|c|c|c|}
\hline & penumpang & \\
\hline & Persiapan & R.Reparasi \\
\hline \multirow{3}{*}{$\begin{array}{l}\text { Pengelola } \\
\text { terminal } \\
\text { pelabuhan }\end{array}$} & Parkir & Area Parkir \\
\hline & $\begin{array}{l}\text { Kegiatan } \\
\text { Administrasi }\end{array}$ & R. Administrasi \\
\hline & $\begin{array}{l}\text { Kegiatan } \\
\text { Pengelolaan } \\
\text { terminal }\end{array}$ & $\begin{array}{l}\text { R.Pengelola } \\
\text { Terminal }\end{array}$ \\
\hline
\end{tabular}

\subsection{Analisis Lokasi}

Menentukan lokasi yang sesuai untuk pelabuhan dan memiliki potensi wisata tepi laut. Dengan dasar pertimbangan yaitu terletak di Provinsi Banten, berpotensi untuk pembangunan pelabuhan, memiliki potensi wisata, sesuai dengan kebutuhan ruang dan memiliki sarana dan prasarana pendukung.

Berdasarkan pembagian wilayah kerja pembangunan dan pembagian wilayah pengembangan potensi wisata provinsi banten (Lampiran 1), maka tapak yang direncanakan berada di Wilayah Kerja Pembangunan (WKP) II dan Wilayah Pengembangan Pariwisata (WPP) B meliputi: Kota Cilegon dan Kabupaten Serang, tepatnya di jalan Pulo Ampel Kecamatan Bojonegara dengan peruntukan pembangunan pelabuhan dan pengembangan wisata pantai.

\subsection{Analisis Pencapaian}

Pencapaian ke dalam kawasan harus mudah diakses dan memiliki pembagian sirkulasi yang jelas antara sirkulasi zona pelabuhan dan zona rekreasi.

1. Tujuan: menentukan main entrane, menentukan service entrance, membagi zona sirkulasi.

2. Dasar Pertimbangan: kemudahan akses, arus kendaraan dan potensi jalan, tingkat keamanan, sirkulasi pengunjung pelabuhan dan rekreasi

3. Proses analisis

Main Entrance (ME)

Mudah dijangkau dan strategis, tidak mengganggu kelancaran lalu lintas, terbuka untuk publik, nyaman dan aman bagi pengguna.

Side Entrance (SE) 
Tidak mengganggu keberadaan ME. Membantu sirkulasi kegiatan servis dan pemadam kebakaran (Gambar 7).

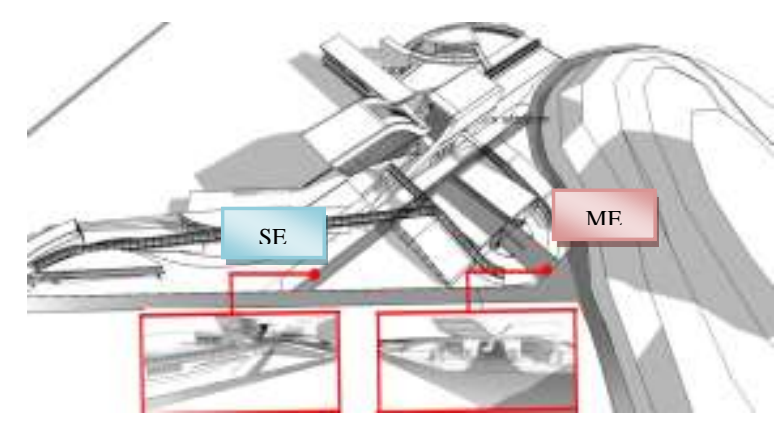

Gambar 7. Pola Pencapaian

Sirkulasi

Recreational Waterfront Harbour menggabungkan kegiatan pelabuhan dengan kegiatan rekreasi yang bersifat semi publik dan publik. Kedua kegiatan tersebut akan menimbulkan sirkulasi yang crowded, maka dilakukan pembagian sirkulasi (Gambar 8).

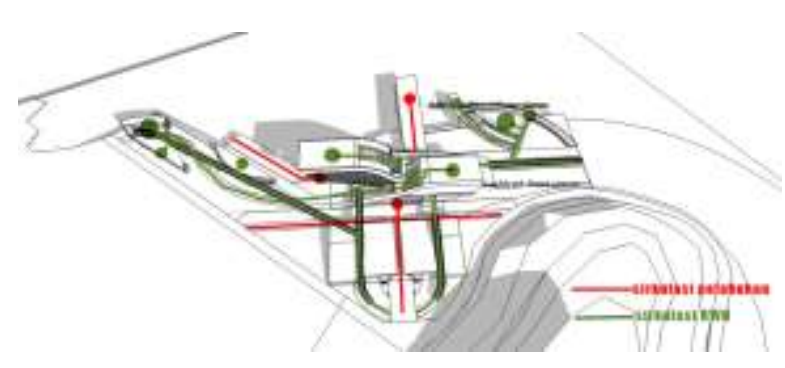

Gambar 8. Pola Sirkulasi

\subsection{Analisis View}

Sebagai area rekreasi pasif, analisa view tapak harus dipertimbangkan untuk mendapatkan view-view menarik di sekitar tapak. Bagian utara tapak memiliki view ke arah laut meliputi view laut dan kegiatan berlabuh, dan bagian barat tapak memiliki view pegunungan. Penataan Recreational Waterfront diarahkan pada kedua view tersebut. Titik view yang direncanakan terdiri menjadi dua titik, yaitu titik yang mengarah ke view laut lepas, dan titik yang mengarah ke view kegiatan berlabuhnya kapal.
Dengan zona view sebagai berikut:

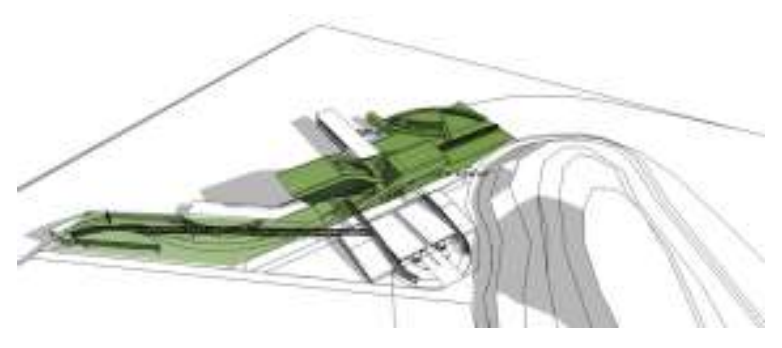

Gambar 9. Zona View

Untuk titik yang mengarah ke view kegiatan berlabuh, direncanakan desain titik berupa menara pandang, karena untuk melihat view tersebut membutuhkan ketinggian, agar tidak mengalami blocking kapal (Gambar 10).

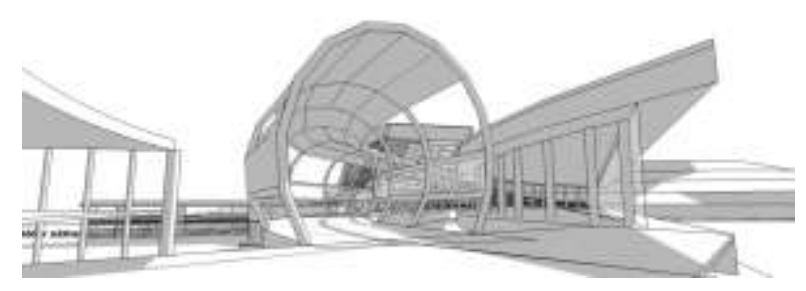

Gambar 10. Menara Pandang

Sedangkan titik yang mengarah ke laut lepas, didesain path-path dan cafe (Gambar 11).

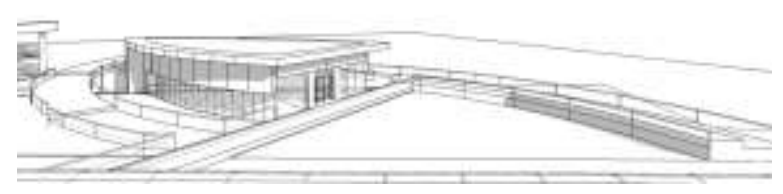

Gambar 11. Path dan Cafe

\subsection{Penekanan Analogi Pada Bentuk Dasar, Tata Massa dan Tampilan}

\subsubsection{Bentuk Dasar}

Dasar pertimbangan dari analisa bentuk dasar bangunan Recreational Waterfront Harbour adalah analogi bentuk pergerakan air, yakni: pergerakan fold, cusp, ecliptic umbilic, dan hyperbolic umbilic.

Bentuk pergerakan air fold dan cusp ini diaplikasikan pada zona embarkasi, 
debarkasi dan pelayanan pengelola. Bentuk dasar bangunan utama terminal Recreational Waterfront Harbour menggunakan pendekatan gabungan bentuk pergerakan air fold dan cusp, karena karakter pergerakannya yang simetris, cepat dan stabil seperti sirkulasi satu arah pada kegiatan di terminal.

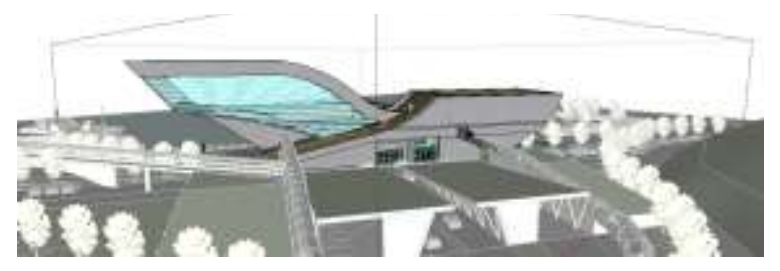

Gambar 12. Bentuk Dasar Bangunan Terminal

\subsubsection{Tata Massa}

Dasar pertimbangan dari analisa analogi pada pola tata massa bangunan ini adalah bentuk tapak dan bentuk pergerakan air hiperbolic umbilic dan ecliptic umbilic. Kedua bentuk tersebut akan diaplikasikan pada penataan lansekap waterfront. Bentuk pergerakan air hiperbolic umbilic diaplikasikan pada penataan waterfront sirkulasi atas dan ecliptic umbilic pada sirkulasi bawah (Gambar 13).

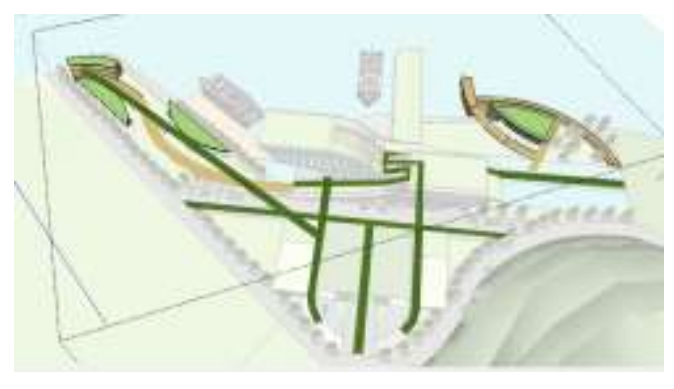

Gambar 13. Penataan Recreational Waterfront

\subsubsection{Tampilan}

Dasar pertimbangan dari analisa analogi biologis pada tampilan bangunan ini adalah 4 karakter sifat Frank Lloyd Wright. Pada tiap elemen pembentuk massa/fasad bangunan, digunakan tekstur dari bentuk alami material, kaca, beton, dan kayu. Elemen kaca juga dipilih agar bangunan dan lingkungan site terkesan harmonis.

Selain itu path menuju Recreational Waterfront juga direncanakan melewati gedung terminal pelabuhan itu sendiri, sehingga batas antara tapak dan bangunan lebih menyatu. Gedung terminal sendiri merupakan pusat dari Recreational Waterfront Harbour, dimana dalam gedung ini terjadi aktifitas berlabuh dan rekreasi.

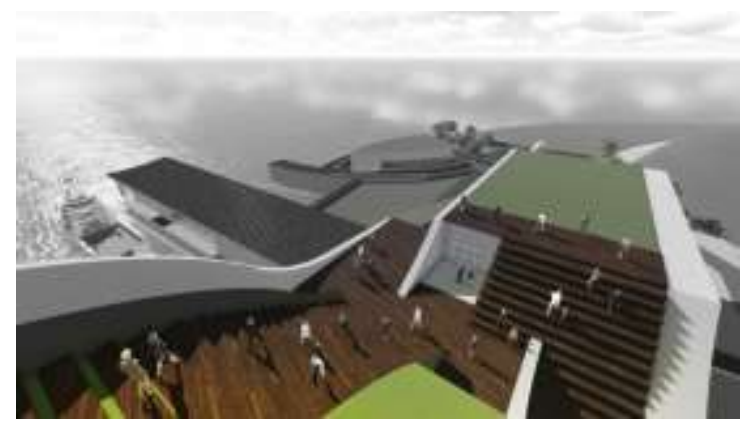

Gambar 14. Bangunan Terminal RWH

\subsection{Analisa Struktur}

Dasar pertimbangan yaitu bentuk dan dimensi bangunan serta kondisi tanah dan angin.

Berdasarkan bentuk dasar yang direncanakan, pada massa zona embarkasi dan debarkasi/terminal penumpang, bentuk dasar bangunan melengkung, sehingga sistem struktur atap yang digunakan adalah sistem struktur yang dapat membentuk lengkung contohnya space frame dan struktur cangkang.

Material konstruksi yang digunakan untuk penutup atap adalah plat panel baja, kayu dan lapisan roof garden. Untuk mendukung struktur atap tersebut, maka rangka atap yang digunakan adalah rangka truss baja dan space frame.

Pada bagian badan bangunan digunakan sistem rigid frame untuk menjaga stabilitas struktur secara keseluruhan. Material konstruksi yang digunakan adalah beton bertulang.

Karena tapak berada di area perairan dan daratan, maka sebagai penopang, sistem pondasi yang digunakan adalah sistem pondasi footplate dan tiang pancang pada 
daerah dengan kondisi tanah yang gembur/perairan.

Letak tapak yang berada di tepi laut mengakibatkan tapak banyak menerima angin berupa angin laut yang berasal dari utara tapak, selain besarnya intesitas pergerakan angin, angin laut pada tapak inipun membawa sifat asin dari laut, sehingga dapat membuat besi berkorosi. Material yang digunakan diantaranya adalah beton, kaca, kayu, steinless dan zinclaume sejenis galvanis yang tahan karat.

\section{KESIMPULAN (KONSEP DESAIN)}

Dari hasil analisa serta hasil korelasi dari beberapa data di atas, maka diperoleh hasil berupa desain Recreational Waterfront Harbour sebagai berikut.

Nama Pelabuhan :Recreational

Waterfront Harbour

Lokasi : Jl. Pulo Ampel

Luas Lahan $: 18000 \mathrm{~m}^{2}$

Luas Bangunan : $6000 \mathrm{~m}^{2}$

Daya Tampung : 2362 orang/hari

Kegiatan : Berlabuh dan rekreasi.

Konsep analogi biologis diterapkan pada bentuk dasar, tata massa dan tampilan pelabuhan.

Bentuk terminal merupakan aplikasi dari gabungan analogi bentuk fold dan cusp (Gambar 15).

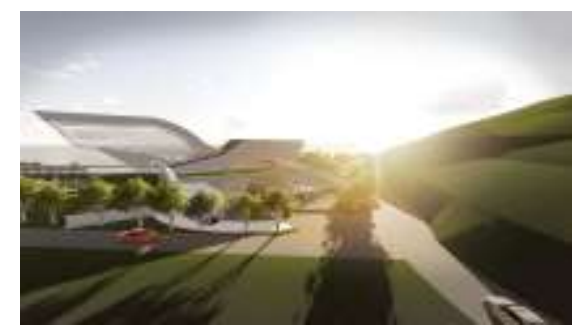

Gambar 15. Bentuk Terminal

Penataan Recreational Waterfront merupakan aplikasi dari analogi bentuk ecliptic umbilic dan hyperbolic umbilic (Lampiran 2). Sedangkan tampilan interior dan eksterior terminal mengaplikasikan penggunaan bahan menurut sifat analogi biologis Frank Lloyd Wright.

\section{REFERENSI}

Triatmodjo, Bambang, DEA. 2009. Perencanaan Pelabuhan. Yogyakarta : Beta Offset.

Pius Wijoyo, Honggo. 2012. Terminal Penumpang Kapal Laut Pelabuhan Harbour Bay Pulau Batam. Yogyakarta.

Tascen. 1895. Frank Lloyd Wright, Bratislaya : Centrum.

Zarzar, dkk. 2008. Understanding Meaningful Environments, IOS Press TU Delft. 


\section{LAMPIRAN 1}

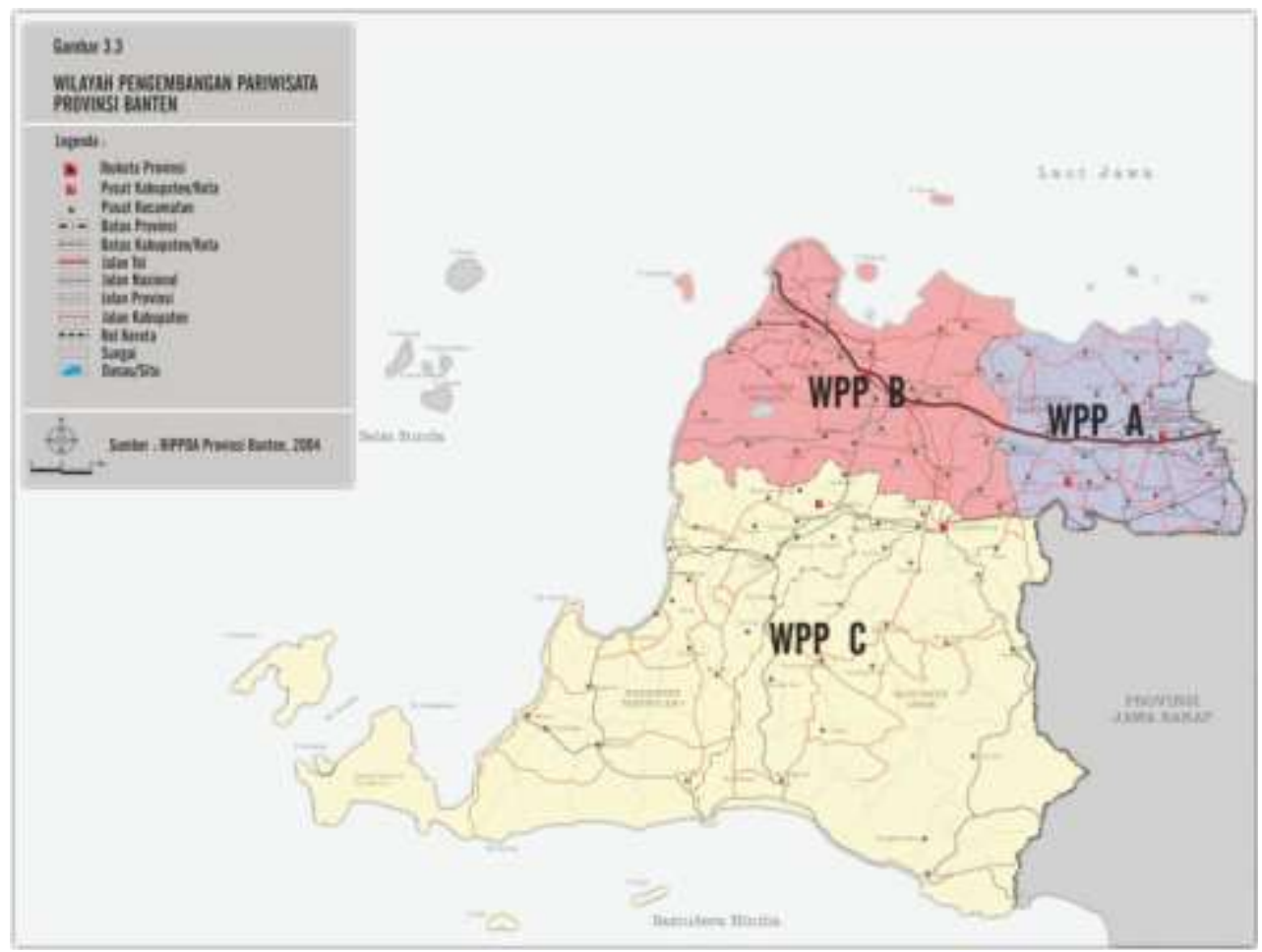

LAMPIRAN 2

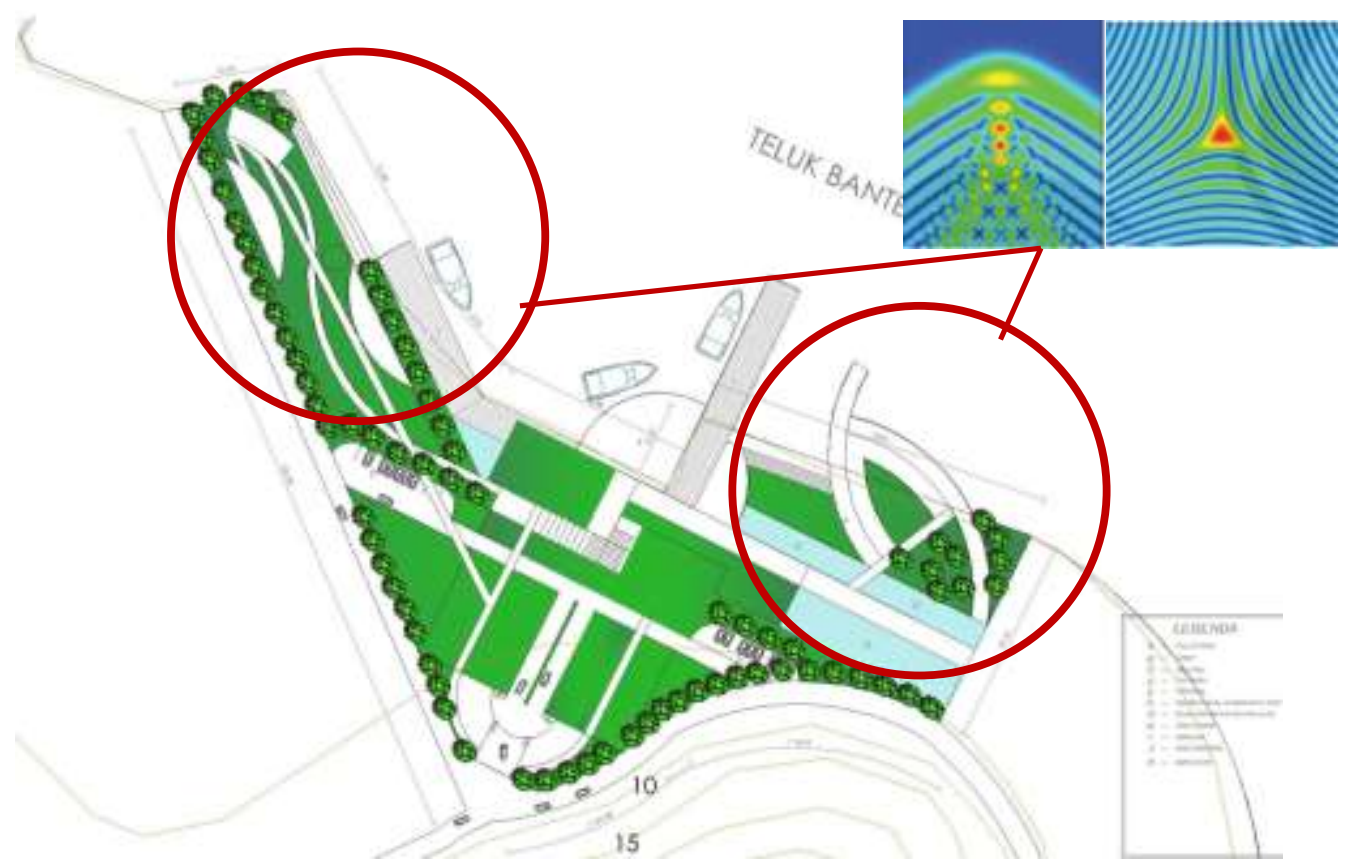

